\title{
A Rare Cause of Left Ventricular Mass: Cardiac Hemangioma
}

\author{
Cihan Altın1, Hakan Güllü2 2 Ziya Gökalp Bilgel2, Mustafa Yılmaz², Tuba Canpolat², Öner Gülcan4
}

\author{
1Department of Cardiology, Başkent University of School of Medicine, İzmir, Turkey \\ ${ }^{2}$ Department of Cardiology, Başkent University of School of Medicine, Adana, Turkey \\ ${ }^{3}$ Department of Pathology, Başkent University of School of Medicine, Adana, Turkey \\ ${ }^{4}$ Department of Cardiovascular Surgery, Başkent University of School of Medicine, Adana, Turkey
}

Cardiac hemangiomas are uncommon tumors of the heart and have been primarily documented as isolated case reports in the literature (1-5). Herein, we present a case of a 56-year-old female having an incidentally identified left ventricular mass. She had no history of cardiac or systemic disease and no clinical symptoms other than mild palpitation. Cardiac imaging tools revealed a hyperechoic, rounded, mobile mass with clear borders, originating from the anteroseptal wall of the left ventricle and protruding into the left ventricular cavity (Figure 1a-c). Preoperative coronary angiography demonstrated that the tumor was fed by septal coronary arteries and the contrast medium was pooling within the tumor area creating the "tumor blush" appearance (Figure 1d). The patient was successfully operated, and the pedunculated mass measuring $2.3 \times 1.5 \times 1.0 \mathrm{~cm}$ was completely excised (Figure 1e). The pathological diagnosis
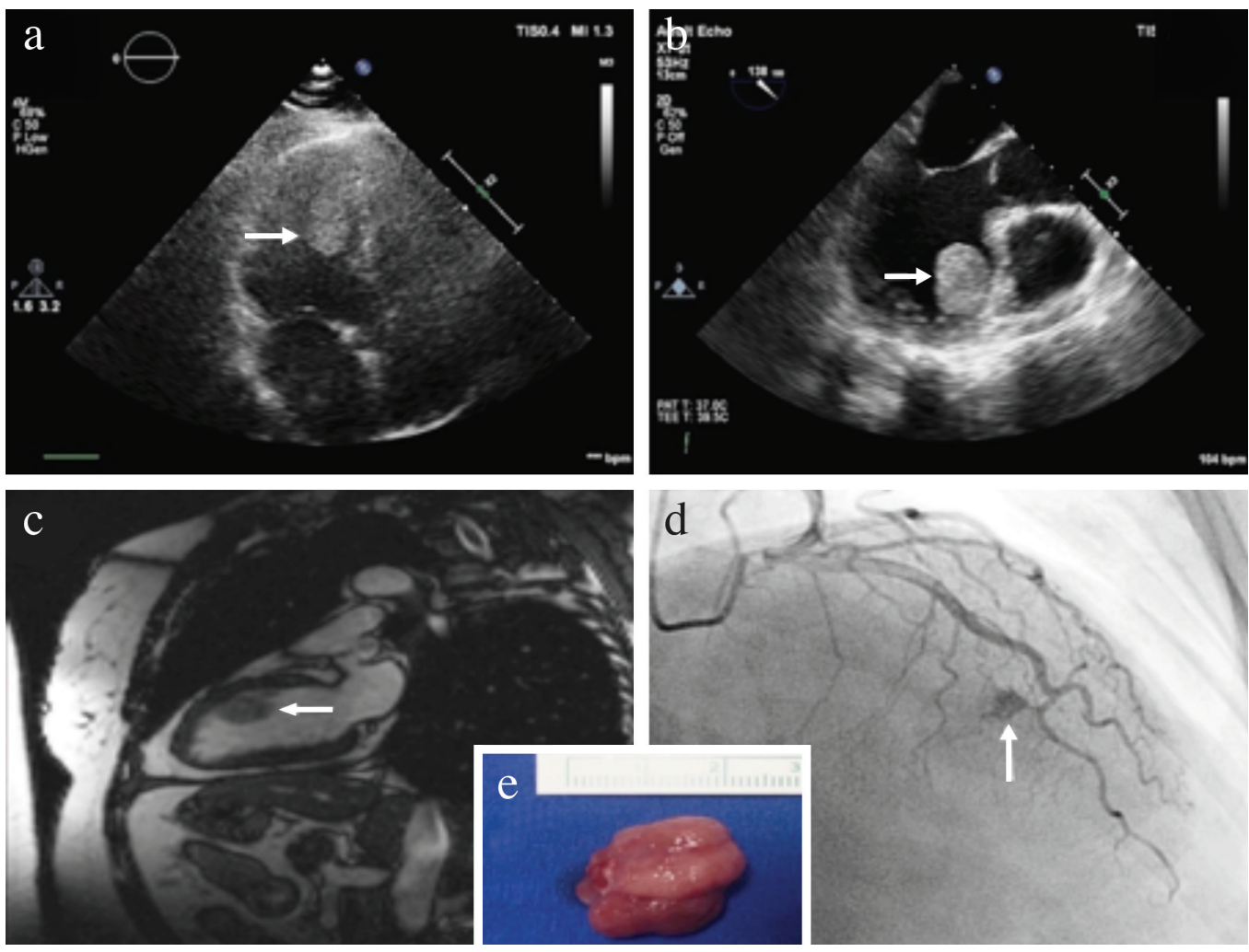

FIG. 1. a-e. Preoperative transthoracic echocardiography; apical four-chamber view showing a hyperechoic, round, mobile mass (arrow) (a). Transesophageal echocardiography revealed a homogenous, round, pedunculated mass (arrow) originating in the anteroseptal wall of the left ventricle (b). A round, hyperintense mass (arrow) originating in the anteroseptal wall of

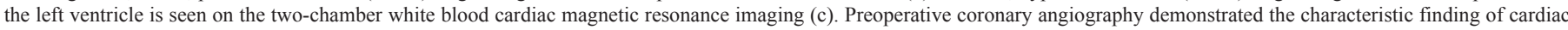
hemangioma "tumor blush" (arrow), which highlights the vascular nature of the tumor (d). Image of the excised cardiac mass measuring $2.3 \times 1.5 \times 1.0 \mathrm{~cm}(\mathrm{e})$.

Our abstract has been accepted as oral presentation in 33 ${ }^{\text {th }}$ Turkish Cardiology Congress 2017

Address for Correspondence: Dr. Cihan Altın, Department of Cardiology, Başkent University of School of Medicine, İzmir, Turkey

Phone: +905324654309 e-mail: drcihanaltin@hotmail.com ORCID ID: orcid.org/0000-0002-3996-5681

Received: 4 October $2017 \quad$ Accepted: 22 March 2018 • DOI: 10.4274/balkanmedj.2017.1334

Available at www.balkanmedicaljournal.org

Cite this article as:

Altın C, Güllü H, Bilgel ZG, Yılmaz M, Canpolat T, Gülcan Ö. A Rare Cause of Left Ventricular Mass: Cardiac Hemangioma. Balkan Med J 2018;35:348-9

${ }^{\circ}$ Copyright 2018 by Trakya University Faculty of Medicine / The Balkan Medical Journal published by Galenos Publishing House. 
was reported to be hemangioma (Figure 2). She had an uneventful recovery without any complication and was discharged on the postoperative $5^{\text {th }}$ day. Informed consent was obtained from the patient to publish this case report.

As echocardiography has become an easily accessible tool, the incidence rates of cardiac masses have dramatically increased. According to surgical and autopsy reports, the incidence of primary cardiac tumors has been reported to be $0.001 \%-0.5 \%$, and approximately $75 \%$ of them are benign $(1,2)$. Cardiac hemangioma, a vascular tumor of the heart, accounts for $5 \%$ of these benign cardiac tumors (2-4). In the majority of cases, they do not cause any symptom and are diagnosed incidentally, whereas some tumors can be symptomatic. Symptoms can arise as a consequence

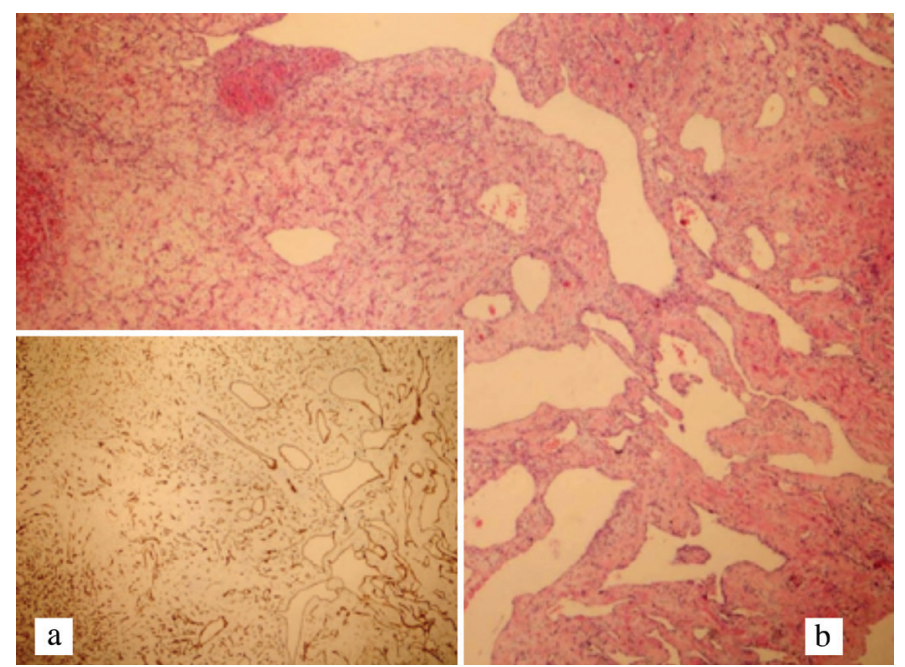

FIG. 2. a, b. Diffuse staining of the vascular endothelial cells with CD34 antibody at $\times 100$ magnification (a), Variations in size and dilated vessels in an edematous stroma; H\&E staining, $\times 100$ magnification (b). of the following tumor evolution: compression, infiltration, rupture, embolization, and growth. Life-threatening complications, including outflow tract obstruction, coronary insufficiency, heart failure, pericardial tamponade, thromboembolia, dysrhythmia, and even sudden cardiac death, can be noticed (1-5). Clinical presentation depends on the location, size, and expansion of the tumor. Since the natural course of these tumors is quite variable and unpredictable, surgical resection is the treatment of choice $(1,2)$. Patients with a resectable cardiac hemangioma have good surgical outcome and prognosis. Although recurrence has been reported in limited cases (4), postoperative long-term outcome is favorable. In our case, there was no evidence of recurrence at the $10^{\text {th }}$-month of follow-up.

In conclusion, among primary cardiac tumors, hemangiomas are relatively rare. Nevertheless, clinicians should consider cardiac hemangioma in the differential diagnosis of cardiac masses, especially in patients with a typical angiographic "tumor blush" appearance, which demonstrates the vascular nature of the tumor.

Conflict of Interest: No conflict of interest was declared by the authors.

\section{REFERENCES}

1. McManus B, Lee CH. Primary tumors of the heart. In: Libby P, Bonow RO, Mann DL, Zipes DP, Braunwald E, editors. Braunwald's Heart Disease. 8th ed. Philadelphia: Elsevier Inc; 2008:1815-29.

2. Song JY, Sung SY, Hsu PS, Lin CY, Tsai YT, Tsai CS. Silent Left Ventricular Hemangioma. Acta Cardiol Sin 2013;29:562-4.

3. Esmaeilzadeh M, Jalalian R, Maleki M, Givtaj N, Mozaffari K, Parsaee M. Cardiac cavernous hemangioma. Eur J Echocardiogr 2007;8:487-9.

4. Brizard C, Latremouille C, Jebara VA, Acar C, Fabiani JN, Deloche A, et al. Cardiac hemangiomas. Ann Thorac Surg 1993;56:390-4.

5. Iba Y, Watanabe S, Akimoto T, Abe K, Koyanagi H. Pedicled cardiac hemangioma with right ventricular outflow tract obstruction. Jpn J Thorac Cardiovasc Surg $2005 ; 53: 269-71$ 